\title{
Ammonia-assimilating enzymes in the basidiomycete fungus Pleurotus ostreatus
}

\author{
V. Mikeš, ${ }^{1}+$ M. Zofall, ${ }^{1}$ M. Chytil, ${ }^{1}$ J. Fulneček ${ }^{1}$ and L. Scháněl ${ }^{2}$ \\ Author for correspondence: V. Mikeš. Tel: +33 80633275. Fax : +3380633265 .
}

Departments of

Biochemistry ${ }^{1}$ and

Microbiology2, Faculty of

Science, Masaryk University,

Kotláŕská 2, 61137 Brno,

Czech Republic

\begin{abstract}
L-Glutamate and L-aspartate are the natural nitrogen sources preferred by the fungus Pleurotus ostreatus. In the vegetative mycelium NAD-dependent glutamate dehydrogenase (NAD-GDH) and glutamine synthetase (GS) were both present, but the highest level of these enzymes was found in the fruiting body. NAD-GDH was derepressed by ammonia and repressed by higher concentrations of L-glutamate. Otherwise, the level of the enzyme in mycelium was independent of the nitrogen source. GS was derepressed by ammonia, L-glutamate, L-aspartate and L-alanine. Repression of GS was observed in the presence of L-glutamine, L-arginine, nitrate, urea and low concentrations of ammonia. An increase in the ratio of glucose to nitrogen resulted in a decrease in the level of GS in the mycelium. The $K_{m}$ values of NAD-GDH for 2-

oxoglutarate, ammonia, NADH, L-glutamate and NAD ${ }^{+}$were $2.9 \mathrm{mM}, 3.3 \mathrm{mM}$, $11 \mu \mathrm{M}, 0.18 \mathrm{mM}$ and $62 \mu \mathrm{M}$, respectively. The $K_{m}$ values of GS for L-glutamate and ammonia were 2.5 and $0.27 \mathrm{mM}$, respectively. The repression of $\mathrm{GS}$ and derepression of NAD-GDH in the presence of low concentrations of ammonia together with glutamate or aspartate could be explained by an inhibition or repression of some amino acid permeases by ammonia. The absence of NADP-dependent glutamate dehydrogenase and glutamate synthase together with the apparent mode of regulation of NAD-GDH and GS synthesis suggest that $P$. ostreatus assimilates ammonia via GS and NAD-GDH. However, a dissimilatory role of NAD-GDH in the deamination of L-glutamate, due to its very low $K_{m}$ for L-glutamate, is not excluded.
\end{abstract}

Keywords: Pleurotus ostreatus, glutamate dehydrogenase, glutamine synthetase, ammonia assimilation

\section{INTRODUCTION}

Nitrogen, one of the most important biogenic elements, is transported into the living cell in an inorganic (nitrate, nitrite, ammonia) or an organic form (amino acids, urea, other nitrogen compounds). A key role is played by ammonia either transported into the cell or formed therein as a metabolite of nitrate, nitrite, urea, amino acids, etc. Three principal enzymes are involved in ammonia assimilation: glutamate dehydrogenase (GDH) (EC 1.4.1.4) and two enzymes utilized at low ammonia concentrations, glutamine synthetase (GS) (EC 6.3.1.2) and glutamate synthase (GOGAT) (EC 1.4.1.13).

†Present address: Laboratoire de Phytopharmacie, INRA, Centre de Dijon, Domaine d'Epoisse, BV 1540, 21034 Dijon Cedex, France.

Abbreviations: GDH, glutamate dehydrogenase; GS, glutamine synthetase; GOGAT, glutamate synthase; NAD(NADP)-GDH, NAD- (NADP-)dependent glutamate dehydrogenase.
In contrast to plants, where the flux of nitrogen is oriented from an inorganic source through amino acids to proteins, in fungi the system includes both anabolic and catabolic activities and, consequently, a sophisticated mechanism of regulation (Jennings, 1988). The metabolism of nitrogen has been best characterized in Neurospora crassa, Saccharomyces cerevisiae, Aspergillus nidulans and Candida utilis (Hammond \& Wood, 1985). These fungi utilize many nitrogen sources of which the preferred are ammonia, L-glutamate and L-glutamine.

GDH is the key enzyme in fungi. NADP-dependent GDH (NADP-GDH) apparently catalyses the synthesis of glutamate whereas the NAD-dependent enzyme (NAD-GDH) catalyses its deamination. Although the molecular structure and allosteric behaviour of the enzymes in $N$. crassa are known, the regulation of the synthesis of GDH is not clear (Molder et al., 1975).

In Coprinus cinereus the activities of GS, NAD-GDH and 
NADP-GDH increase during the carpophore development and they probably act as an ammonia-scavenging system as ammonia apparently inhibits basidiospore formation (Moore et al., 1987). The levels of NAD-GDH in mycelium and in fruiting-body caps of Agaricus bisporus are very similar while the activity of NADP-GDH is higher in developing caps (Baars et al., 1991).

The basidiomycete Pleurotus ostreatus is an edible mushroom cultivated on lignocellulosic wastes and makes up a steadily increasing part of the international mushroom market. The biodegradation of lignin by 'white rot' fungi is effectively stimulated by nitrogen limitation (Commanday \& Macy, 1985), but the metabolism of nitrogen in this fungus has not been studied in detail. Here, we describe a study of its ammonia-assimilating enzymes.

\section{METHODS}

Culture. Pleurotus ostreatus, wild strain, was obtained from the collection of the Feedstuffs Research Institute (no. 3), Ivanka pri Dunaji, Slovakia, as a gift from Dr A. Ginterova. The culture was maintained on $2 \%(\mathrm{w} / \mathrm{v})$ malt agar. The fruiting bodies were obtained from the Mushroom Station Zástrizly (Kroměříz). The caps of young fruiting bodies (diameter $5 \mathrm{~cm}$ ) cultivated on wheat straw were cut, frozen in liquid nitrogen and stored at $-60^{\circ} \mathrm{C}$.

Media and growth conditions. The complex liquid medium contained $2 \%(\mathrm{w} / \mathrm{v})$ malt extract, $0.05 \%$ yeast extract and $0.1 \mathrm{mM} \mathrm{KH}_{2} \mathrm{PO}_{4}$. The $\mathrm{pH}$ was adjusted to 5.0 with $\mathrm{NaOH}$. The nitrogen concentration in the complex medium containing $2 \%$ malt extract determined colorimetrically after mineralization (Schwartz, 1971) was $13 \mathrm{mM}$. The synthetic medium contained: $50 \mathrm{mM} \mathrm{KH} \mathrm{PO}_{4}, 0.4 \mathrm{mM} \mathrm{CaCl}, 0.8 \mathrm{mM} \mathrm{MgSO}, 16.6$ or $55.5 \mathrm{mM}$ glucose and, per litre, $0.1 \mathrm{~g}$ malt extract and $20 \mathrm{ml}$ trace metals $\left(0.8 \mathrm{mM} \mathrm{CuSO}_{4}, 0.34 \mathrm{mM} \mathrm{ZnSO}_{4}, 0.5 \mathrm{mM} \mathrm{MnCl}_{2}\right.$, $0.2 \mathrm{mM}$ sodium molybdate, $3.5 \mathrm{mM} \mathrm{FeSO}_{4}$ and $0.15 \mathrm{mM}$ EDTA). If the mycelium cultivated in the complex medium was used for the inoculation, malt extract was omitted from the synthetic medium. After addition of the nitrogen source the $\mathrm{pH}$ was adjusted to $5 \cdot 0$. The inoculum was cultivated in $100 \mathrm{ml}$ conical flasks with cultivation medium poured on glass beads $(4 \mathrm{~mm})$. A small piece of agar with mycelium was put on the surface of the glass beads and the stationary cultivation was carried out for $8 \mathrm{~d}$ at $27^{\circ} \mathrm{C}$. Thereafter, the mycelium was homogenized by shaking and used for the inoculation.

The cultivation of submerged cultures was carried out in $250 \mathrm{ml}$ conical flasks with $60 \mathrm{ml}$ medium. After inoculation with $1-3 \%$ $(\mathrm{v} / \mathrm{v})$ inoculum the stationary cultures were maintained for $24 \mathrm{~h}$ at $27^{\circ} \mathrm{C}$ and then shaken at 150 r.p.m. for $3 \mathrm{~d}$. Mycelial pellets were filtered through nylon tissue, washed with $100 \mathrm{mM}$ Tris/ $\mathrm{HCl}, \mathrm{pH} 7 \cdot 4$, containing $2 \mathrm{mM}$ EDTA and stored at $-60^{\circ} \mathrm{C}$.

Preparation of cell-free extract. The mycelium or sliced caps were homogenized by grinding with glass beads (diameter $0.15 \mathrm{~mm}$ ) in liquid nitrogen. To $1 \mathrm{~g}$ of the powder $1 \mathrm{ml} 100 \mathrm{mM}$ Tris/ $\mathrm{HCl}, \mathrm{pH} 7 \cdot 4,2 \mathrm{mM}$ EDTA and $2 \mathrm{mM} 2$-mercaptoethanol was added, and the suspension was centrifuged at $15000 \mathrm{~g}$ $\left(30 \mathrm{~min}, 4^{\circ} \mathrm{C}\right)$. The supernatant was used for enzyme assays.

Enzyme assays. All enzyme activities were measured at $25^{\circ} \mathrm{C}$. The transferase activity of GS was measured according to Bender et al. (1977) in $100 \mathrm{mM}$ imidazole/ HCl, pH 6.5, containing $200 \mathrm{mM}$ L-glutamine, $60 \mathrm{mM}$ hydroxylamine $/ \mathrm{HCl}$,
$20 \mathrm{mM}$ sodium arsenate, $1 \mathrm{mM} \mathrm{MnCl}_{2}$ and $0.3 \mathrm{mM}$ ADP. The incubation was performed for 15-20 min and stopped with a stop mixture. The $A_{534}$ of the complex of $\gamma$-glutamylhydroxamic acid was measured (molar absorption coefficient $8501 \mathrm{~mol}^{-1} \mathrm{~cm}^{-1}$ ). The activity is expressed in nkat ( $\mathrm{nmol} \gamma$ glutamylhydroxamic acid $\mathrm{s}^{-1}$ ) per $\mathrm{mg}$ protein.

The biosynthetic reaction of GS (the synthesis of L-glutamine) was measured as the increase in the concentration of inorganic phosphate in a mixture containing $100 \mathrm{mM}$ imidazole $/ \mathrm{HCl}$, pH 6.5, $40 \mathrm{mM}$ L-glutamate, $5 \mathrm{mM} \mathrm{NH}_{4} \mathrm{Cl}$ and $2 \mathrm{mM}$ ATP: $1 \mathrm{ml}$ of the mixture was incubated for $30-60 \mathrm{~min}$ with the extract and the reaction was stopped with $0.5 \mathrm{ml} 3 \%(\mathrm{v} / \mathrm{v})$ $\mathrm{HClO}_{4}$. After the centrifugation, $1.8 \mathrm{ml} 0.8 \% \mathrm{FeSO}_{4}$ in $0.1 \mathrm{M}$

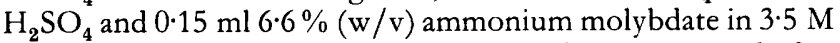
$\mathrm{H}_{2} \mathrm{SO}_{4}$ were added to the supernatant and the $A_{650}$ read after 10 min. The blank did not contain glutamate and $\mathrm{NH}_{4} \mathrm{Cl}$. The activity was expressed in nkat (nmol phosphate $\mathrm{s}^{-1}$ ) per $\mathrm{mg}$ protein.

The measurement of the biosynthetic activity of GS is complicated by the high level of ATPase and phosphatase. An alternative assay has been developed by substituting hydroxylamine for ammonia, and the amount of $\gamma$-glutamylhydroxamate produced can then be determined spectrophotometrically (Bender et al., 1977). GS is able to catalyse a transfer of the $\gamma$-glutamyl group from L-glutamine to hydroxylamine. The rate of this transfer is 10 -fold higher than that of the synthetic reaction.

The synthetic activity of GS was measured by the hydroxylamine method in a solution containing $100 \mathrm{mM}$ imidazole $/ \mathrm{HCl}$,

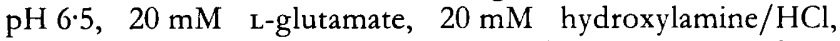
$50 \mathrm{mM} \mathrm{MgCl}$ and $2 \mathrm{mM} \mathrm{ATP}$. The incubation was carried out for 30-60 $\mathrm{min}$ and stopped as described above.

The aminating activity of GDH was estimated spectrophotometrically as the rate of oxidation of NADH or NADPH. To a mixture containing $100 \mathrm{mM}$ Tris $/ \mathrm{HCl}, \mathrm{pH} 8.2,30 \mathrm{mM} \mathrm{2-}$ oxoglutarate and $0 \cdot 12 \mathrm{mM} \mathrm{NADH}$ or NADPH, the cell-free extract was added and the blank reaction was measured. The reaction was started by addition of $30 \mathrm{mM} \mathrm{NH}_{4} \mathrm{Cl}$. The blank reaction, which represented maximally $10 \%$, was subtracted. The activity was expressed in nkat (nmol NADH or NADPH $\mathrm{s}^{-1}$ ) per $\mathrm{mg}$ protein. The activity of GOGAT was measured in the mixture described above but with $\mathrm{NH}_{4} \mathrm{Cl}$ replaced by $30 \mathrm{mM}$ L-glutamine.

The deaminating activity of GDH was estimated as the rate of reduction of NAD. To a mixture of $100 \mathrm{mM}$ Tris $/ \mathrm{HCl}, \mathrm{pH} 9 \cdot 0$, and $0.1 \mathrm{mM}$ NAD, the cell-free extract was added, which resulted in the reduction of NAD by endogenous substrates. After $2 \mathrm{~min}$ this reaction stopped, and the deamination was started by the addition of $12 \mathrm{mM}$ L-glutamate.

Protein determination. Protein was determined by the method of Bradford (1976) with bovine serum albumin as the standard.

\section{RESULTS}

\section{Effect of nitrogen source on the growth of mycelium}

$P$. ostreatus utilized a wide spectrum of organic and inorganic sources. The biomasses obtained after 4 days of cultivation in synthetic medium with differing nitrogen sources are summarized in Table 1 . The concentration of nitrogen carried over from the complex medium to the synthetic medium during inoculation was $0.39 \mathrm{mM}$. Table 1 shows that L-glutamate and L-aspartate were the best nitrogen sources whereas nitrate was the poorest. 
Table 1. Biomass of mycelium of $P$. ostreatus after $4 \mathrm{~d}$ cultivation in the synthetic medium as a function of nitrogen source

Inoculum $(1.8 \mathrm{ml})$ cultivated in complex medium was used for inoculation of $60 \mathrm{ml}$ synthetic medium (three replicates). After $4 \mathrm{~d}$ the inocula were filtered, lyophilized and weighed. The standard deviation is given in parentheses.

\begin{tabular}{|lc|}
\hline $\begin{array}{c}\text { Nitrogen source } \\
\mathbf{( 5 ~} \mathbf{~ m} \mathbf{M})\end{array}$ & $\begin{array}{c}\text { Dry weight } \\
\mathbf{( m g )}\end{array}$ \\
\hline None & $3 \cdot 0(0 \cdot 5)$ \\
$\mathrm{KNO}_{\mathbf{3}}$ & $5 \cdot 4(0 \cdot 6)$ \\
$\mathrm{NH}_{\mathbf{4}} \mathrm{Cl}$ & $9 \cdot 0(0 \cdot 8)$ \\
L-Arginine & $10 \cdot 1(0 \cdot 5)$ \\
L-Alanine & $11 \cdot 2(0 \cdot 7)$ \\
L-Glutamine & $11 \cdot 3(0 \cdot 8)$ \\
Urea & $13 \cdot 0(0 \cdot 8)$ \\
L-Aspartate & $16 \cdot 7(0 \cdot 9)$ \\
L-Glutamate & $17 \cdot 3(0 \cdot 8)$ \\
\hline
\end{tabular}

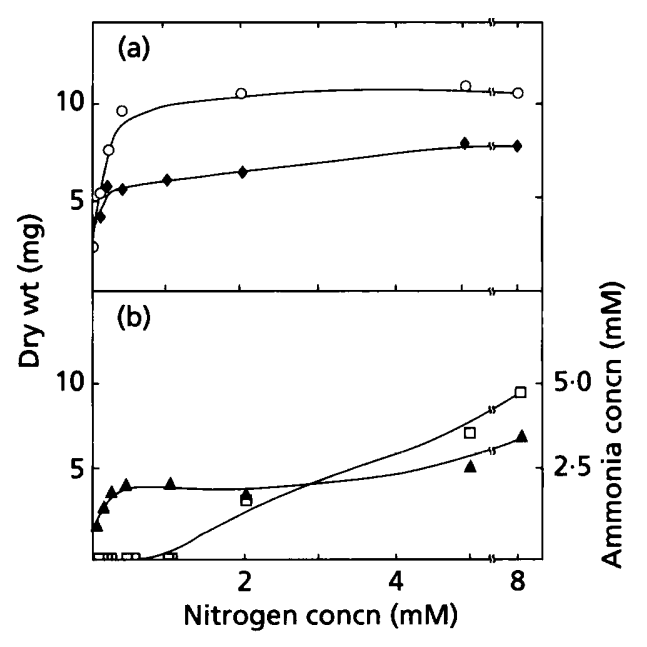

Fig. 1. Biomass of vegetative mycelium of $P$. ostreatus in synthetic medium of different nitrogen concentrations. An inoculum of $0.6 \mathrm{ml}$ cultivated in the complex medium with $1 \%$ $(w / v)$ malt extract was used to inoculate $60 \mathrm{ml}$ synthetic medium. The concentration of glucose was $16.7 \mathrm{mM}$. (a) Cultures grown with ammonia (O, biomass determined after $4 \mathrm{~d})$ or glutamate $(\bullet, 3 \mathrm{~d})$. (b) Cultures grown with urea ( $\boldsymbol{A}$, $3 \mathrm{~d})$. The concentration of ammonia in the medium after $3 \mathbf{d}$ is also given ( $\square$ ). The number of replicates was two; the curves were made on the basis of mean values. The relative standard deviations were $5-15 \%$. The determination of ammonia was made with three replicates; the relative standard deviations were $2-3 \%$.

The dependence of growth on the concentration of ammonia, L-glutamate and urea is shown in Fig. 1. In this case the nitrogen concentration carried over from the complex to the synthetic medium was only $0.065 \mathrm{mM}$. Ammonia proved to be a very efficient source of nitrogen.
The concentration of $2 \mathrm{mM}$ did not limit growth. The concentration necessary to achieve a biomass after 3-4 d equal to a half of the maximal growth $\left(\mathrm{C}_{50}\right)$ was less than $0.2 \mathrm{mM}$. Similar results were obtained with $\mathrm{L}$-glutamate, for which $\mathrm{C}_{50}$ was $0.5 \mathrm{mM}$.

The presence of ammonia in the cultivation medium with urea as the nitrogen source after $4 \mathrm{~d}$ showed that urea was probably metabolized via urease. The amount of ammonia in the medium did not represent more than $30 \%$ of urea nitrogen. However, we were unable to find any traces of urease in the cell-free extract of mycelia cultivated on urea.

\section{Ammonia-assimilating enzymes}

The activities of GS, GDH and GOGAT were investigated in cell-free extracts of mycelia and fruiting bodies of P. ostreatus. GS and NAD-GDH were present in fruitingbody caps and vegetative mycelium, but neither GOGAT nor NADP-GDH was found whether cultivation was on malt extract, L-glutamate or ammonia. The GS transferase activity in both fruiting bodies and mycelium was accompanied by synthetic and biosynthetic activities, which confirms that the enzyme responsible was GS. In malt extract cultures the ratio of the activities of transferase and synthetic reactions was $12.5-16$ and 28 in fruiting bodies and mycelium, respectively; that of the biosynthetic and synthetic reactions was 1 in both fruiting bodies and mycelium.

During the storage of cell-free extract of fruiting bodies at $5{ }^{\circ} \mathrm{C}$, the transferase activity was stable whereas the synthetic and biosynthetic activity diminished slowly. However, we had some difficulties in measuring the synthetic and biosynthetic activities in mycelia cultivated in the synthetic medium because during the long incubation times at $25^{\circ} \mathrm{C}$ the enzyme was inactivated, probably owing to oxidation catalysed by traces of heavy metals in the cell-free extracts, as described for Escherichia coli GS (Fisher \& Stadtman, 1992).

The activity of GDH diminished by $50 \%$ during the storage overnight at $5{ }^{\circ} \mathrm{C}$.

The highest levels of GS (transferase reaction) and NADGDH (aminating reaction) were found in fruiting bodies and were 11.2 and $1.51 \mathrm{nkat}\left(\mathrm{mg}\right.$ protein) ${ }^{-1}$, respectively. The enzyme activities in cell-free extracts of mycelium cultivated in malt extract and synthetic medium containing different nitrogen sources are summarized in Table 2. The highest level of NAD-GDH was found in mycelium cultivated in malt extract. Ammonia markedly derepressed NAD-GDH. In contrast, a higher concentration of L-glutamate in cultivation medium resulted in partial repression of the enzyme, The activities of NADGDH in mycelia cultivated on all the other substrates were very similar. An increase in concentration of glucose from 16.6 to $55.5 \mathrm{mM}$ had a small effect on the specific activity of NAD-GDH.

The specific activity of GS in mycelium was substantially influenced by the source of nitrogen. L-Glutamate, L- 
Table 2. Specific activity [nkat (mg protein) ${ }^{-1}$ ] of GS (transferase reaction) and NAD-GDH (aminating reaction) in mycelium of $P$. ostreatus for different cultivation conditions in synthetic medium

An inoculum of $1.8 \mathrm{ml}$ cultivated in the respective synthetic medium was used for inoculation of $60 \mathrm{ml}$ synthetic medium. After $4 \mathrm{~d}$ the mycelia were harvested and frozen. Each value represents the mean of three replicates with the standard deviation in parentheses. ND, Not determined.

\begin{tabular}{|c|c|c|c|}
\hline Nutrients & $\begin{array}{l}\text { Nitrogen source } \\
\text { concn }(\mathrm{mM})\end{array}$ & GS & NAD-GDH \\
\hline Malt extract $(2 \%, \mathrm{w} / \mathrm{v})$ & & $3.83(0 \cdot 08)$ & $1.37 \quad(0 \cdot 03)$ \\
\hline \multirow[t]{14}{*}{ Glucose $(16.7 \mathrm{mM})$ plus: } & $\mathrm{NH}_{4} \mathrm{Cl}(5)$ & $7 \cdot 50(0 \cdot 15)$ & $0.505(0.002)$ \\
\hline & $\mathrm{NH}_{4} \mathrm{Cl}(1)$ & $3 \cdot 70(0 \cdot 11)$ & $0.230(0.002)$ \\
\hline & $\mathrm{NH}_{4} \mathrm{Cl}(0.5)$ & $2.90(0.06)$ & $0.098(0.001)$ \\
\hline & Glutamate (5) & $8.83(0.33)$ & $0.178(0.003)$ \\
\hline & Glutamate (1) & $9 \cdot 14(0 \cdot 30)$ & $0.375(0.004)$ \\
\hline & Alanine (5) & $10 \cdot 45(0 \cdot 42)$ & $0.310(0.006)$ \\
\hline & Aspartate (5) & $10 \cdot 90(0 \cdot 33)$ & $0.320(0.005)$ \\
\hline & Arginine (5) & $3 \cdot 40(0 \cdot 14)$ & $0.280(0.003)$ \\
\hline & Glutamine (5) & $2.65(0 \cdot 11)$ & $0.450(0.002)$ \\
\hline & Urea (5) & $2 \cdot 50(0 \cdot 13)$ & $0 \cdot 415(0 \cdot 008)$ \\
\hline & $\mathrm{KNO}_{3}(5)$ & $4 \cdot 18(0 \cdot 13)$ & ND \\
\hline & Glutamate (4) $+\mathrm{NH}_{4} \mathrm{Cl}(1)$ & $2.88(0.06)$ & $0.320(0.003)$ \\
\hline & $\mathrm{NH}_{4} \mathrm{Cl}(4)+$ glutamate $(1)$ & $5.40(0 \cdot 15)$ & $0.450(0.004)$ \\
\hline & Aspartate (4) $+\mathrm{NH}_{4} \mathrm{Cl}(1)$ & $3 \cdot 90(0 \cdot 10)$ & $0.404(0 \cdot 004)$ \\
\hline \multirow[t]{5}{*}{ Glucose $(55.5 \mathrm{mM})$ plus: } & $\mathrm{NH}_{4} \mathrm{Cl}(5)$ & $1.56(0 \cdot 05)$ & $0.236(0.004)$ \\
\hline & Glutamate (5) & $4.63(0 \cdot 13)$ & $0.129(0.002)$ \\
\hline & Aspartate (5) & $6.83(0.27)$ & $0 \cdot 280(0 \cdot 004)$ \\
\hline & Glutamine (5) & $1.38(0.05)$ & $0.340(0 \cdot 007)$ \\
\hline & Urea (5) & $1 \cdot 15(0.06)$ & $0.360(0.006)$ \\
\hline
\end{tabular}

alanine, L-aspartate and ammonia all derepressed GS. A decrease in ammonia concentration resulted in a marked decrease in the level of GS in cells, as was the case with NAD-GDH. The level of GS after growth with $1 \mathrm{mM}$ ammonia was not maximal although this concentration of ammonia was not growth limiting (see Fig. 1). L-Glutamine repressed GS. Similar repression of GS was found in mycelia cultivated in nitrate, urea or L-arginine. An increase in the glucose concentration to $55.5 \mathrm{mM}$ in all cases gave a lower enzyme activity, especially when ammonia was the nitrogen source, in which case glucose was the only source of carbon.

The addition of $1 \mathrm{mM}$ ammonia together with $4 \mathrm{mM} \mathrm{L-}$ glutamate or L-aspartate to the synthetic medium repressed GS and derepressed NAD-GDH. In contrast, the addition of $1 \mathrm{mM}$ glutamate to $4 \mathrm{mM}$ ammonia had no marked effect on the activity of NAD-GDH and GS.

\section{Kinetic parameters of GDH and GS}

The kinetic parameters of both enzymes were determined in crude extracts of fruiting body caps. The $\mathrm{pH}$ optima of the transferase, synthetic and biosynthetic reactions of GS were all about $\mathrm{pH} 6.5$. The $\mathrm{pH}$ optima of the aminating and deaminating reactions of NAD-GDH were $\mathrm{pH} 8 \cdot 2$
Table 3. Apparent $K_{\mathrm{m}}$ values of GS and NAD-GDH from fruiting body caps of $P$. ostreatus

Each value of $K_{\mathrm{m}}$ was determined on the basis of 10 substrate concentrations. All Lineweaver-Burk plots were linear with correlation coefficients of $0.97-0.99$.

\begin{tabular}{|lll|}
\hline Substrate & \multicolumn{2}{c|}{$\boldsymbol{K}_{\mathrm{m}}(\mathrm{mM})$} \\
\cline { 2 - 3 } & NAD-GDH & GS \\
\hline $\mathrm{NH}_{4}^{+}$ & $3 \cdot 3$ & $0 \cdot 27$ \\
2-Oxoglutarate & $2 \cdot 9$ & \\
NADH & $0 \cdot 011$ & \\
L-Glutamate & $0 \cdot 18$ & $2 \cdot 5$ \\
NAD $^{+}$ & 0.062 & \\
\hline
\end{tabular}

and $9 \cdot 0$, respectively. The $K_{\mathrm{m}}$ values of both enzymes measured in fruiting body extracts are summarized in Table 3. The constants were calculated from kinetic measurements of the reaction rates varying the concentration of one substrate, the other substrates being in excess. It is evident from the 10 -fold lower $K_{\mathrm{m}}$ value that GS had a higher affinity for ammonia than NAD-GDH. 
In contrast, the $K_{\mathrm{m}}$ for glutamate of GDH was much lower than that of GS.

\section{DISCUSSION}

L-Glutamate, L-glutamine and ammonia are the preferred nitrogen sources utilized by fungi. L-Glutamate can be synthesized efficiently by GDH, GOGAT or via transaminases. The role of GDH in fungi is both catabolic and anabolic. It is generally accepted that NADP-GDH serves as an anabolic enzyme, whereas NAD-GDH is utilized for deamination of glutamate. NAD-GDH in both $N$. crassa and $A$. nidulans is derepressed by glutamate and repressed by a high concentration of glucose, and in $S$. cerevisiae it is repressed by ammonia (Smith et al., 1975). NADP-GDH shows a complementary pattern: it is repressed by glutamate in $N$. crassa and $A$. nidulans (Smith et al., 1975).

The vegetative mycelium of higher fungi contains both NAD- and NADP-GDH. NAD-GDH is derepressed and NADP-GDH repressed by urea in Coprinus cinereus (Fawole \& Casselton, 1972). Both enzymes are found in fruiting bodies and their activities increase during development. Moore et al. (1987) suggested that GDH and GS act as an efficient scavenging system for ammonia, which would otherwise inhibit sporulation. Baars et al. (1991) detected and partially purified NAD- and NADPGDH of Agaricus bisporus. They proposed an opposite role for both enzymes and suggested that NADP-GDH plays an important role in sporulation. Al-Gharawi \& Moore (1977) suggested, on the basis of kinetic measurements, that NAD-GDH could play both anabolic and catabolic roles.

The vegetative mycelium and fruiting bodies of P. ostreatus contain GS and NAD-GDH, the highest level of both enzymes being contained in fruiting bodies. No traces of GOGAT and NADP-GDH were found in this fungus. In fungi, GOGAT activity has been reported in $S$. cerevisiae, $N$. crassa and Stropharia semiglobata (Brown et al., 1973; Hummelt \& Mora, 1980; Schwartz et al., 1991).

The data on NAD-GDH of $P$. ostreatus suggest that it is a synthetic enzyme. It was derepressed in mycelium by ammonia and repressed by higher concentrations of $\mathrm{L}$ glutamate. This is supported by the fact that the $K_{\mathrm{m}}$ values of NAD-GDH of $P$. ostreatus for ammonia and NADH were much lower than the corresponding values of NADGDH of C. cinereus (Al-Gharawi \& Moore, 1977) and Agaricus bisporus (Baars et al., 1991). On the other hand, the $K_{\mathrm{m}}$ of NAD-GDH for glutamate, which is 100 -fold and 20 -fold lower than the values for the $A$. bisporus and the $C$. cinereus enzymes, respectively, suggests a deaminating role for NAD-GDH in $P$. ostreatus. The growth curve of $P$. ostreatus (Fig. 1 ) and a value of $C_{50}$ comparable with the $K_{\mathrm{m}}$ for glutamate suggest that glutamate could be metabolized by the GDH pathway.

The synthesis of L-glutamine is catalysed by only one enzyme, GS. Glutamine serves as a donor for the synthesis of the other amino acids and many other nitrogen compounds. In $S$. cerevisiae and $N$. crassa glutamine is metabolized via glutaminases or the glutamine- $\omega$-amidase pathway, where glutamine is transaminated to yield different amino acids and 2-oxoglutaramate is hydrolysed, giving rise to 2-oxoglutarate and ammonia (Calderon et al., 1985; Cooper \& Meister, 1977). GS in S. cerevisiae and $N$. crassa was derepressed by glutamate and repressed by glutamine (Minehart \& Magasanik, 1992; Mora, 1990). As shown in Table 2, GS of P. ostreatus was derepressed by ammonia, glutamate, aspartate and alanine. The concentrations of these amino acids are regulated by means of transaminases and the ratio glutamate: ammonia:glutamine regulated by means of GDH and GS. An increase in the glucose : nitrogen ratio resulted in all cases in a decrease in the GS level. The lowest levels of the enzymes were found if the mycelium was cultivated in L-glutamine or with nitrogen sources giving rise to ammonia. Urea is assimilated in $P$. ostreatus via urease (Fig. 1), nitrate is probably assimilated by nitrate reductase and nitrite reductase. The assimilation of arginine in higher fungi has not been studied, but in $S$. cerevisiae it is metabolized via arginase, giving rise to urea and Lornithine (Wiame et al., 1985). It is not excluded that the repression of GS in $P$. ostreatus in the presence of urea, nitrate and arginine could be explained by the low internal concentration of ammonia released from those nitrogen sources.

The addition of a low concentration of ammonia together with glutamate and aspartate to cultivation medium caused a repression of GS in $P$. ostreatus. The uptake systems for nitrogen compounds play an important role in the regulation of nitrogen metabolism. In yeast, L-glutamate is taken up by three different systems: two permeases of dicarboxylic amino acids and a general amino acid permease. Some of them are effectively inhibited or repressed by low concentrations of ammonia (Wiame et al., 1985). Thus, it is possible that the repression of GS and derepression of NAD-GDH when a low ammonia concentration is added to glutamate is due to the inhibition of glutamate and aspartate transport and preferential utilization of ammonia. The increase in the internal concentration of glutamine as a result of the presence of ammonia and glutamate (both are the substrates of GS) cannot be a signal of repression of GS because no marked effect was observed after the addition of a low glutamate concentration to ammonia (Table 2).

The high affinity of GS for ammonia suggests that the assimilation of low ammonia concentrations would be catalysed by GS. This is confirmed by the respective growth curve (Fig. 1) and $\mathrm{C}_{50}(0.2 \mathrm{mM})$ comparable with $K_{\mathrm{m}}$ for ammonia. At higher concentrations however, both NAD-GDH and GS could act simultaneously in assimilation of ammonia.

\section{ACKNOWLEDGEMENTS}

We are very grateful to Dr A. Ginterova for the gift of cultures of Pleurotus and for stimulating discussions and to Professor H. J. M. Op den Camp, Catholic University of Nijmegen, for his advice concerning the methods of enzymology of higher fungi. 


\section{REFERENCES}

Al-Gharawi, A. \& Moore, D. (1977). Factors affecting the amount of the activity of glutamate dehydrogenases of Coprinus cinereus. Biochim Biophys Acta 496, 95-102.

Baars, J. J. P., Op den Camp, H. J. M., Steyns, L. S. W., van der Drifts, C., Vogels, G. D. \& van Griensven, L. J. C. D. (1991). Glutamate dehydrogenases of Agaricus bisporus. In Science and Cultivation of Edible Fungi, pp. 234-240. Edited by M. J. Maher. Rotterdam \& Brookfield: A. A. Balkema.

Bender, P. A., Janssen, K. A., Resnick, A. D., Blumenberg, M., Foor, F. \& Magasanik, B. (1977). Biochemical parameters of glutamine synthetase from Klebsiella aerogenes. I Bacteriol 129, 1001-1009.

Bradford, M. M. (1976). A rapid and sensitive method for quantitation of microgram quantities of protein utilizing the principle of protein-dye binding. Anal Biochem 72, 248-254.

Brown, C. M., Burn, V. J. \& Johnson, B. (1973). Presence of glutamate synthase in fission yeast and its possible role in ammonia assimilation. Nat New Biol 246, 115-116.

Calderon, J., Morette, E. \& Mora, J. (1985). $\omega$-Amidase pathway in the degradation of glutamine in Neurospora crassa. J Bacteriol 161, 807-809.

Commanday, F. \& Macy, J. M. (1985). Effect of substrate nitrogen on lignin degradation by Pleurotus. Arch Microbiol 142, 61-65.

Cooper, A. J. L. \& Meister, A. (1977). The glutamine transaminase$\omega$-amidase pathway. Crit Rev Biochem 4, 281-303.

Fawole, M. O. \& Casselton, P. J. (1972). Observation of the regulation of glutamate dehydrogenase activity in Coprinus lagopus. $J$ Exp Bot 23, 530-551.

Fisher, M. T. \& Stadtman, E. R. (1992). Oxidative modification of Escherichia coli glutamine synthetase. Decreases in the thermodynamic stability and specific changes in the active site conformation. J Biol Chem 267, 1872-1880.

Hammond, J. B. W. \& Wood, D. A. (1985). Metabolism, biochemistry and physiology. In Biology and Technology of the Cultivated Musbrooms, pp. 63-80. Edited by P. B. Flegg, D. M. Spencer \& D. A. Wood. Chichester \& New York: John Wiley.
Hummelt, G. \& Mora, J. (1980). Regulation and function of glutamate synthase in Neurospora crassa. Biochem Biophys Res Commun 96, 1688-1694.

Jennings, D. H. (1988). Some perspectives of nitrogen and phosphorus metabolism in fungi. In Nitrogen, Phosphorus and Sulphur Utilisation by Fungi, pp. 1-31. Edited by L. Boddy, R. Marchant \& D. J. Read. New York, New Rochelle, Melbourne \& Sydney: Cambridge University Press.

Minehart, P. L. \& Magasanik, B. (1992). Sequence of the GLN1 gene of Saccharomyces cerevisiae. Role of upstream region in regulation of glutamine synthetase expression. J Bacteriol 174, 1828-1836.

Molder, A. A., Wooton, J. C., Baron, A. J., Chambers, G. J. K. \& Fincham, J. R. S. (1975). The amino acid sequence of Neurospora crassa NAD-specific glutamate dehydrogenase. Biochem $J$ 149, 757-772.

Moore, D., Horner, J. \& Liu, M. (1987). Co-ordinate control of ammonium scavenging enzymes of fruit-body caps of Coprinus cinereus avoids inhibition of sporulation by ammonium. FEMS Microbiol Lett 44, 239-242.

Mora, J. (1990). Glutamine metabolism and cycling in Neurospora crassa. Microbiol Rev 54, 293-303.

Schwartz, M. (1971). Clinical aspects of L-asparaginase. Methods Enzymol 178, 861-865.

Schwartz, T., Kusnan, M. B. \& Fock, H. P. (1991). The involvement of glutamine synthetase/glutamate synthase in ammonia assimilation by the basidiomycete fungus Stropharia semiglobata. J Gen Microbiol 137, 2253-2258.

Smith, E. L., Austen, B. M., Blumenthal, K. M. \& Nyc, J. F. (1975). Glutamine dehydrogenases. In The Enzymes, vol. 11, pp. 293-367. Edited by P. D. Boyer. New York, San Francisco \& London: Academic Press.

Wiame, J. M., Grenson, M. \& Arts, M. N. (1985). Nitrogen catabolic repression in yeast and filamentous fungi. Adv Microb Pbysiol 26, $2-59$.

Received 31 August 1993; revised 25 October 1993; accepted 5 November 1993. 